\title{
Pegylated interferon $2 a$ and $2 b$ in combination with ribavirin for the treatment of chronic hepatitis C in HIV infected patients
}

\author{
Ravinder Dhillon \\ Simona Rossi \\ Steven K Herrine \\ Department of Medicine, \\ Division of Gastroenterology \\ and Hepatology, Thomas Jefferson \\ University, Philadelphia, PA, USA
}

Correspondence: Steven K Herrine Division of Gastroenterology and Hepatology, Thomas Jefferson University, I32 S. I0th Street, Suite 450, Philadelphia, PA 19004, USA

$\mathrm{Tel}+2159555247$

Fax +215 5032146

Email steven.herrine@jefferson.edu

\begin{abstract}
Coinfection with hepatitis $\mathrm{C}$ virus (HCV) and HIV is an increasingly recognized clinical dilemma, particularly since the advent of highly active antiretroviral therapy. Several studies of this population have demonstrated both more rapid progression of liver disease and poorer overall prognosis compared to $\mathrm{HCV}$ monoinfected patients. Consensus guidelines, based primarily on the results of 4 major randomized trials, recommend treatment with peginterferon and ribavirin for 48 weeks in coinfected patients. However, this current standard of care is associated with lower response rates to therapy than those seen in monoinfected patients. Important predictors of response include HCV genotype, pretreatment HCV RNA level, and presence of rapid virologic response (RVR) and early virologic response (EVR). Use of weight-based ribavirin dosing appears to be safe and enhances the likelihood of sustained virologic response (SVR). Adverse effects most commonly encountered are anemia and weight loss. Mitochondrial toxicity can occur in the setting of concomitant nucleoside reverse transcriptase inhibitor use, especially didanosine, abacavir, and zidovudine, and these should be discontinued before initiation of ribavirin therapy. Discontinuation of therapy should be considered in patients failing to demonstrate EVR, though ongoing trials are investigating a potential role for maintenance therapy in these patients. Peginterferon combined with weight-based ribavirin is appropriate and safe for treatment of HCV in HIV - HCV coinfected patients. This review summarizes the data supporting these recommendations.
\end{abstract}

Keywords: hepatitis C, human immunodeficiency virus, peginterferon, ribavirin

\section{Introduction}

Coinfection with hepatitis C virus (HCV) and HIV affects 200,000-300,000 individuals in the US alone (Sherman et al 2002). As the two viruses share a common route of transmission, the prevalence of chronic HCV among all HIV patients has been reported in the range of $25 \%$ to $30 \%$ (Thomas 2002). Among HIV patients with a history of intravenous drug use, prevalence rates rise as high as 75\%-90\% (Alter 2006). Rates of coinfection via sexual transmission are increasing (McGovern and Bica 2002). In Europe and the US, since the advent of highly active antiretroviral therapy (HAART), HCV-related liver disease has become one of the leading causes of morbidity and mortality in HIV patients (Puoti et al 1997; Bica et al 2001).

Persons with HIV coinfection tend to have higher HCV viral loads and are less likely to clear the HCV spontaneously (Daar et al 2001). Compared with HCVmonoinfected patients, coinfected patients have a more rapid progression of hepatic fibrosis (Graham et al 2001); an increased risk of developing cirrhosis, decompensated liver disease, and HCC. In addition, they have persistently higher HCV viremia; and a higher risk of HAART-related hepatotoxicity (Benhamou et al 1999; McGovern and Bica 2002; Rauch et al 2005). Unlike HCV-monoinfected patients, HCV viral 
load appears to have prognostic significance in coinfected patients, and emerging data indicate that it may be an important predictive indicator of HIV disease progression (Daar et al 2001). Whether or not coinfection causes a poorer overall prognosis in HIV disease remains controversial (Greub et al 2000).

In addition to bearing a poorer prognosis, coinfected patients also have lower response rates to therapy than those with HCV alone. Thus, the appropriate management of HCVrelated chronic liver disease in HIV patients presents substantial challenges for even the most experienced clinicians. Prior to undertaking therapy, there are a number of issues for the physician to address. These include prioritization of HAART vs anti-HCV therapy, the role of liver biopsy, and interactions between, and hepatotoxicity of, HAART and anti-HCV therapy. These important considerations have recently been reviewed elsewhere (McGovern and Bica 2007) This review will focus on the evidence guiding optimal dosages and duration of therapy, predictors of response, and toxicity concerns once the decision to treat has been made. Maximizing response to $\mathrm{HCV}$ therapy in $\mathrm{HIV}-\mathrm{HCV}$ coinfected patients first requires a basic understanding of the therapeutic approach to HCV-monoinfection.

\section{Therapy of chronic HCV}

Sustained viral response (SVR), defined as a level of serum HCV RNA that is undetectable 24 weeks after the end of therapy, is the established goal of therapy in HCV infection. This benchmark has been shown to predict durable long-term response (Lau et al 1998). Furthermore eradication of circulating HCV RNA has been shown to reduce liver injury and, more controversially, even reverse liver fibrosis (Poynard et al 2002). Histologic response - especially improvement of fibrosis and necroinflammation - has been proposed as a secondary goal of therapy, particularly in HIV - HCV coinfected patients (Barreiro et al 2006). Finally, eradication of HCV RNA may decrease the risk of HAART-related hepatotoxicity (McGovern 2004; Labarga et al 2007).

\section{Interferon}

Type 1 interferons (IFNs) are naturally occurring cytokines that have important innate antiviral, antiproliferative, and immunomodulatory properties. To date, the alpha IFNs have yielded the most promising results as pharmaceutical agents. The human alfa IFN family consists of at least 15 subtypes, ranging in molecular size from $17.5 \mathrm{kD}$ to $23 \mathrm{kD}$, each containing 165 or 166 amino acids, with approximately $80 \%$ sequence homology between members of the group of proteins (Wills 1990). When parenterally administered, IFN binds to and leads to dimerization of IFN cell-surfacereceptor subunits. Activation of the receptor-associated Janus-activated kinase 1 (Jak1) and tyrosine kinase 2 (Tyk2) then, in turn, lead to activation of transcription proteins 1 and 2 (STAT 1 and STAT 2). The activated STAT1/2 complex then migrates to the cell nucleus, forming a complex with IFN-regulatory factor 9 (IRF-9) where interaction with cellular DNA leads to expression of IFN-stimulated genes (ISGs). As a result, a wide variety of gene products, many of which are involved in antiviral activity, are expressed (Tilg 1997; deVeer et al 2001; Sen 2001; Gale 2003; Bekisz et al 2004; Feld and Hoofnagle 2005).

The addition of ribavirin, a synthetic guanosine analogue, to IFN significantly improves response rates, particularly for patients with HCV genotypes 2 and 3 (McHutchison et al 1998; Pol et al 2000). Ribavirin may have some inherent antiviral activity against $\mathrm{HCV}$, but its importance as a therapeutic agent appears to be its ability to enhance viral mutagenesis during IFN therapy. However, ribavirin significantly adds to the side effect profile of HCV antiviral therapy regimens, particularly by causing hemolytic anemia. HCV treatment has been further enhanced by the attachment of polyethylene glycol to the IFN molecule (pegylation), which reduces IFN breakdown and clearance, thereby decreasing its immunogenicity and increasing half-life, allowing less frequent weekly dosing schedules while sustaining high IFN levels.

The current standard of care for HCV monoinfection is pegylated IFN alfa and ribavirin (Manns et al 2001; Fried et al 2002). Regimens vary by HCV genotype: for genotypes 1 or 4 , ribavirin dosage is weight-based $(1000 \mathrm{mg} /$ day for weight $<75 \mathrm{~kg}$ and $1200 \mathrm{mg} /$ day for weight $>75 \mathrm{~kg}$ ), while for genotypes 2 or 3 , a lower dose ( $800 \mathrm{mg} /$ day) is prescribed. Similarly, duration of therapy is 48 weeks for patients with genotypes 1 or 4 , and 24 weeks for patients with genotypes 2 or 3 . These schedules have resulted in SVR rates ranging from $45 \%$ to $55 \%$ in groups with genotypes 1 or 4 , and as high as $80 \%$ in groups with genotypes 2 or 3 . Weight-based dosing of ribavirin may add efficacy to this antiviral regimen, especially in patients with higher BMI (Jacobson et al 2007). Factors associated with decreased response include African-American race, obesity, presence of cirrhosis, high viral loads $(>800,000 \mathrm{IU} / \mathrm{mL})$, and genotypes 1 and 4 .

\section{Therapy of HIV - HCV coinfection}

Published recommendations for treatment of HCV-HIV coinfected patients reach consensus on a standard of care 
of pegylated IFN and ribavirin for 48 weeks. These guidelines draw largely upon the results of 4 major randomized trials, the results of which were all published in 2004. These studies demonstrated a consistently superior overall efficacy of pegylated IFN and ribavirin compared with standard IFN and ribavirin in coinfected patients. Nonetheless, overall SVR rates in the pegylated IFN and ribavirin treatment arms were significantly lower than those reported for HCV monoinfection, particularly for genotypes 1 and 4 . These pivotal trials will be described in further detail. (Table 1)

\section{Barcelona}

This single-center, open-label trial randomized 95 patients to IFN alfa-2b plus ribavirin or pegylated IFN alfa-2b plus ribavirin (Laguno et al 2004). Ribavirin was dose-adjusted by body weight (dose range $800-1200 \mathrm{mg} /$ day). Subjects with favorable genotypes (2 and 3 ) and low HCV RNA level $(<800,000 \mathrm{IU} / \mathrm{mL})$ were randomized to 24 weeks of treatment; all others received a full 48 weeks. Dose reduction was allowed for adverse effects according to a defined protocol. Patients with detectable HCV RNA after 24 weeks of therapy were considered failures and therapy was discontinued.
By intention-to-treat analysis SVR was achieved in $44 \%$ of the pegylated IFN group vs. $21 \%$ of the IFN group ( $p=0.017)$. For patients with genotypes 1 and 4, SVR was $38 \%$ for pegylated IFN vs. $7 \%$ for IFN ( $p=0.007)$. For genotypes 2 and 3 , rates of SVR were similar (53\% vs $47 \%$ for pegylated IFN vs IFN, respectively, $p=0.73$ ) and relapse rates approached $23 \%$. On multivariate analysis, genotypes 2 and 3, dose modification, and pegylated IFN therapy were independent predictors associated with SVR.

\section{APRICOT}

This international, multicenter, randomized trial, the largest to date, randomized a total of 868 patients to 48 weeks of treatment with either IFN alfa-2 plus ribavirin, pegylated IFN alfa-2a plus placebo, or pegylated IFN alfa-2a plus ribavirin (Torriani et al 2004). Ribavirin daily dose was $800 \mathrm{mg}$ for all patients. Dose reduction was allowed for adverse effects according to a defined protocol.

By intention-to-treat analysis, SVR was achieved in $40 \%$ of the pegylated IFN plus ribavirin group, vs $20 \%$ of the pegylated IFN plus placebo group $(\mathrm{p}<0.001)$ and $12 \%$ of the IFN plus ribavirin group $(\mathrm{p}<0.001)$. For patients with genotype 1 , SVR rates were $29 \%$ for the pegylated

Table I Baseline characteristics and sustained virologic response rates in subjects randomized to pegylated interferon and ribavirin in four pivotal trials. Reprinted with permission from Shuhart MC. 2007. Hepatitis C and HIV coinfection. Curr Hepatitis Rep, 6:46-53. Copyright (C) 2005 Current Medicine Group LLC.

\begin{tabular}{|c|c|c|c|c|}
\hline & APRICOT $[45 \bullet \bullet]$ & Barcelona $[46 \bullet]$ & ACTG $[47 \bullet]$ & RIBAVIC [48•] \\
\hline Subjects, N & 289 & 52 & 66 & 205 \\
\hline Pegylated interferon & Alfa-2a & Alfa-2b & Alfa-2a & Alfa-2b \\
\hline Ribavirin dose, mg/d & 800 & 800,1000 or 1200 & $600-1000$ (escalated) & 800 \\
\hline Age, y & 39.7 (mean) & 40 (mean) & 45 (median) & 39.5 (mean) \\
\hline Male, \% & 80 & 63 & 79 & 77 \\
\hline African American, \% & II & NR & 32 & NR* \\
\hline Body weight, mean, kg & 72.1 & NR & NR & 67.4 \\
\hline CD4 cell count, cells/ $\mu \mathrm{L}$ & 542 (mean) & 570 (mean) & 495 (median) & 477 (median) \\
\hline HIV RNA, \% undetectable & $60(<50$ copies $/ m L)$ & 70 (<200 copies/mL) & $6 \mathrm{I}(<50$ copies $/ \mathrm{mU}$ & $70(<400$ copies $/ \mathrm{mL})$ \\
\hline Antiretroviral therapy, \% & 84 & 88 & 85 & 83 \\
\hline HCV RNA level in high range, \% & $72(>800,000 \mathrm{IU} / \mathrm{mL})$ & $47(>800,000 \mathrm{IU} / \mathrm{mL})$ & $83(>1,000,000 \mathrm{IU} / \mathrm{mL})$ & $65(>500,000 \mathrm{IU} / \mathrm{mL})$ \\
\hline \multicolumn{5}{|l|}{ HCV genotype, \% } \\
\hline Genotype I & 61 & 55 & 77 & 48 \\
\hline Genotype 2 or 3 & 32 & 37 & $\mathrm{NR}^{+}$ & 38 \\
\hline Genotype 4 & 6 & 8 & $\mathrm{NR}^{+}$ & 13 \\
\hline Other & I & 0 & $N^{\prime}$ & I \\
\hline Bridging fibrosis/cirrhosis, \% & 12 & 30 & II & 39 \\
\hline \multicolumn{5}{|l|}{ Sustained response, $\%$} \\
\hline Genotype I & 29 & $38^{*}$ & 14 & $17^{\ddagger}$ \\
\hline Genotype 2 or 3 & 62 & 53 & $73^{\dagger}$ & 44 \\
\hline Genotype 4 & NR & - & - & - \\
\hline
\end{tabular}

*6\% not of French or Mediterranean descent.

†Non-I genotypes were predominantly 2 or 3 .

*Genotypes I and 4 combined.

Abbreviations: ACTC, AIDS Clinical Trials Croup;APRICOT, AIDS PECASYS Ribavirin International Co-infection Trial; HCV, hepatitis C virus; NR, not reported. 
IFN plus ribavirin group, $14 \%$ for the pegylated IFN plus placebo group, and 7\% for the IFN plus ribavirin group. For patients with genotype 3, SVR rates were $62 \%, 36 \%$, and $20 \%$, respectively. HCV genotype other than 1 and baseline HCV RNA <800,000 IU/mL were associated with increased odds of SVR. Early virologic response (defined as a decrease in the HCV RNA level of $2 \log$ or more by week 12) predicted a higher likelihood of SVR, particularly in the pegylated IFN plus ribavirin group. Only $2 \%$ of total patients who did not have early virologic response went on to have SVR.

Of note, the results of this trial were critical for US FDA approval of pegylated IFN alfa-2a and ribavirin for HCV-HIV coinfected patients. Additional APRICOT findings published in 2006 indicated a histologic response, defined as 2 point or greater reduction in histological activity index (HAI) score, occurred in $69 \%$ of patients with SVR and $43 \%$ of patients without SVR.

\section{ACTG}

Published at the same time as the APRICOT study, this multicenter, randomized trial included a total of 133 patients who were randomized to receive pegylated IFN alfa-2a plus ribavirin or IFN alfa-2a plus ribavirin (Chung et al 2004). Ribavirin was dosed in escalating fashion from 600 to 1000 mg daily in an attempt to reduce anemia. Dose reduction was allowed for adverse effects according to a defined protocol. Subjects with virologic response at week 24 continued treatment, and those without 24-week virologic response underwent liver biopsy and could only continue if they had histologic response (HAI improvement of at least 2 points). Primary end-points were virologic response and safety at week 24, and SVR was among the secondary end-points.

By intention-to-treat analysis, SVR rate was $27 \%$ in the pegylated IFN plus ribavirin group, compared with $12 \%$ in the IFN plus ribavirin group $(\mathrm{p}=0.03)$. For genotype $1, \mathrm{SVR}$ rates were $14 \%$ and $6 \%$, respectively, whereas for nongenotype 1 , SVR rates were $73 \%$ and $33 \%$, respectively. A relapse rate of $33 \%$ was observed in the pegylated IFN group, predominantly from genotype 1 patients, which partly explains the low SVR rate of $14 \%$. Factors predictive of SVR in multivariate analysis included receipt of pegylated IFN, HCV genotype other than 1, absence of prior intravenous drug use, and detectable HIV-1 RNA at entry. None of the patients without early virologic response went on to have SVR (NPR 100\%). Histologic responses were noted in 35\% of virologic nonresponders and $52 \%$ of virologic responders, indicating a possible clinical benefit even in the absence of virologic clearance, and suggesting a role for investigation of maintenance strategies.

\section{RIBAVIC}

This French multicenter, randomized open-label trial included a total of 412 patients who were randomized to receive pegylated IFN alfa- $2 \mathrm{~b}(1.5 \mu \mathrm{g} / \mathrm{kg})$ plus ribavirin or IFN alfa-2b plus ribavirin for 48 weeks (Carrat et al 2004). Ribavirin daily dose was $800 \mathrm{mg}$. Liver biopsy was performed at the end of follow-up. Dose reduction was allowed for adverse effects according to a defined protocol. By intention-to-treat analysis, SVR was obtained in $27 \%$ of the pegylated IFN plus ribavirin group and $20 \%$ of the IFN plus ribavirin group $(p=0.047)$. Less than $1 \%$ of the patients not achieving early viral response went on to have SVR. Among patients with genotype 1 or $4,17 \%$ of the pegylated IFN plus ribavirin group had SVR, compared with $6 \%$ of the IFN plus ribavirin group $(p=0.006)$. For patients with genotype 2,3 , or 5, rates of SVR did not differ between the two treatment groups ( $44 \%$ vs $43 \%$, respectively, $\mathrm{p}=0.88$ ). Predictors of SVR by multivariate analysis included HCV genotypes 2, 3 , or 5 , no protease inhibitor treatment, age $<40$ years, and baseline alanine aminotransferase (ALT) greater than 3 times normal. Histologic benefit was significant only in those who had SVR. In contrast to the APRICOT findings, only $4 \%$ of nonresponders had histologic improvement, defined as a decrease of 2 points or more of fibrosis stage.

These four pivotal trials, while demonstrating a benefit of pegylated IFN alfa-2a or pegylated IFN alfa- $2 b$ in combination with ribavirin for HIV - HCV coinfected individuals, still had lower SVR rates than those for HCV monoinfection. SVR ranged from $27 \%$ to $44 \%$. The higher SVR seen in the Barcelona study, which used ribavirin doses of up to $1200 \mathrm{mg} /$ day, suggests that the dose of ribavirin may play a critical role in determining SVR. The next trial pursues this hypothesis.

\section{PRESCO}

This Spanish multicenter trial aimed to evaluate the efficacy and safety of weight-based RBV dosing as well as extended duration of therapy in coinfected patients (Nunez et al 2007a). A total of 389 patients all received pegylated IFN alfa-2a plus weight-based ribavirin at $1000 \mathrm{mg} /$ day or $1200 \mathrm{mg} /$ day. Patients without early virologic response (EVR) were discontinued, as were patients with detectable HCV RNA at 24 weeks. Genotype 2/3 patients were treated for 24 or 48 weeks, and genotype $1 / 4$ patients were treated for 48 or 72 weeks. Dose reduction was allowed for adverse effects 
according to a defined protocol. By intention-to-treat analysis, $49.6 \%$ of patients achieved SVR. SVR was significantly more frequent in patients with HCV genotypes $2 / 3(72.4 \%)$ than HCV genotypes $1 / 4$ (35\%) ( $\mathrm{p}<0.0001)$. Overall, patients assigned to extended treatment arms demonstrated better treatment responses irrespective of genotype. However, $45 \%$ of patients allocated to the extended treatment arms refused to continue medication beyond the minimum period of therapy, mainly due to patient preference rather than serious adverse events. Definitive conclusions could not be drawn regarding benefit of longer courses of therapy for patients without EVR, owing to the low number of such patients among $\mathrm{HCV}$ genotypes $2 / 3$ and the low number of patients among $\mathrm{HCV}$ genotypes 1/4 completing extended therapy. Multivariate analysis identified HCV genotypes 2/3, baseline HCV RNA $<500,000 \mathrm{IU} / \mathrm{mL}$, and negative HCV RNA at week 12 as independent predictors of SVR.

\section{Predictors of response}

Several factors in the above trials were identified as predictors of SVR. Low pretreatment HCV RNA level, assignment to pegylated IFN, absence of prior intravenous drug use, baseline ALT > 3 times normal, and no dose modification were all associated with higher SVR. Interestingly, neither liver disease stage (all studies excluded only decompensated cirrhosis) nor baseline CD4 count at study entry was associated with SVR in any of these studies. Perhaps the most striking finding was the absence of early virologic response as a predictor of SVR, with a negative predictive value of 98\%-100\%, which seems to suggest that treatment can be discontinued early if EVR has not been reached.

Rapid virologic response (RVR), defined as an undetectable HCV RNA level at 4 weeks of therapy, has been shown to be another important predictor of response. Recently published data from the RIBAVIC study demonstrated that failure to suppress serum HCV RNA levels below 460,000 IU/mL after 4 weeks of therapy was associated with a negative predictive value of $100 \%$ (Payan et al 2007). Similarly, the best positive and negative predictive values (97\%) of SVR in the RIBAVIC trial were obtained in patients with RVR.

Certain factors have additionally been identified as predictors of virologic relapse following cessation of therapy. For instance, recently published PRESCO data indicates lack of RVR is an independent predictor of HCV relapse (relative risk [RR] 2.94; 95\% confidence interval [CI] 1.22-7.09; $\mathrm{p}=0.02)$. Furthermore, use of concomitant HAART also was noted to be associated with relapse $(p=0.04)$ (Nunez et al 2007b). The nucleoside reverse transcriptase inhibitor abacavir has been implicated as an agent that should be particularly avoided during HCV therapy. When used concomitantly with ribavirin, abacavir is associated with a higher risk of early nonresponse to HCV therapy (RR 4.9) (Bani-Sadr et al 2007a). The PRESCO data reveal lower EVR, end of treatment response, and SVR in patients receiving abacavir-based antiretroviral therapy (Vispo et al 2007).

\section{Toxicity}

Interferon administration leads a variety of physical side effects which affect individuals with different frequency and severity. Early side effects include influenza-like symptoms such as myalgias, arthralgias, pyrexia, headache, and lassitude. These side effects tend to subside with longer duration of therapy and clearance of the drug from the system. On the other hand, weight loss has been a persistent and well-established side effect, with several studies demonstrating a significantly higher incidence in coinfected patients receiving pegylated IFN plus ribavirin. One retrospective cohort study found that clinically significant weight loss, defined as at least $5 \%$ of baseline weight, occurred in $76 \%$ of coinfected patients compared with $39 \%$ of HCV-monoinfected patients (Re et al 2007). Similarly, the RIBAVIC investigators found that $29 \%$ of coinfected patients who received at least one dose of anti-HCV treatment developed severe weight loss ( $>10 \%$ of baseline weight), and that these patients were significantly more likely to develop lipodystrophy. Of note, weight loss of at least $5 \%$ that persisted for 24 weeks after completion of anti-HCV therapy is associated with stavudine-based HAART, which has led some investigators to suggest a role for mitochondrial toxicity in the pathogenesis of weight loss (Bani-Sadr et al 2008a).

In addition to weight loss, more persistent side effects with repeated administration of anti-HCV therapy include fatigue, anorexia, and an assortment of neuropsychiatric side effects ranging from mild attention deficits through emotional lability, anger, and depression. Suicide has been described resulting from IFN-related depression (Janssen et al 1994). Serotonin uptake inhibitors and other antidepressants have been used with success in ameliorating neuropsychiatric side effects (Schaefer et al 2005). In the coinfected individual, involvement of a treatment team, including psychiatric support, has been demonstrated to increase compliance to therapy. The use of such a team may also expand the potential pool of patients that can be considered for the rigors of antiviral treatment (Taylor et al 2003).

An issue unique to the coinfected patient and of considerable concern in early trials is the reduction of CD4+ count during therapy. Numerous investigators have noted a reduction in 
CD4+ counts during therapy, although adverse consequences of the reduction appear to be unusual (Soriano et al 2007a). CD4+ cell counts return to normal within 24 weeks of cessation of HCV therapy. The safety of HCV therapy in patients with baseline CD4+ counts below 200 cells $/ \mu \mathrm{L}$ is not clear since the major clinical trials took such a count as exclusion criteria (Laguno et al 2004; Chung et al 2004; Carrat et al 2004). The exception was the APRICOT trial, where CD4+ count as low as 100 cells/ $\mu \mathrm{L}$ was allowed (Torriani et al 2004).

Anemia, a commonly seen complication of anti-HCV therapy, has been observed in higher incidence in coinfected populations. In RIBAVIC, $16 \%$ of patients who received at least one dose of anti-HCV therapy developed severe anemia $(\mathrm{Hb}<10 \mathrm{~g} / \mathrm{dL})$. Multivariate analysis demonstrated a significant risk associated with zidovudine use (odds ratio [OR] 3.27; 95\% CI 1.64-1.54; p = 0.0008) (Bani-Sadr et al 2007b). Moreover, concomitant use or zidovudine and anti-HCV therapy has been associated with higher rates of ribavirin dose reduction and use of epoetin alfa (Alvarez et al 2006). These deleterious consequences may be related to zidovudine-induced reduction of globin mRNA synthesis or zidovudine-induced increases in plasma levels of ribavirin.

Drug-drug interactions are responsible for other considerable toxicities in this population. Chief among these is mitochondrial toxicity from nucleoside analogue reverse transcriptase inhibitors (NRTIs), which may manifest symptomatically with lactic acidosis, pancreatitis, weight loss, or even hepatic decompensation (Lafeuillade et al 2001). This toxicity is most pronounced in patients receiving concomitant anti-HCV therapy and didanosine. The RIBAVIC trial demonstrated an adjusted 46-fold increase in the risk of symptomatic mitochondrial toxicity and an adjusted 8.8-fold increase in the risk of spontaneous hepatic decompensation in such patients (Bani-Sadr et al 2005a, b). Analysis of APRICOT data similarly identified didanosine treatment as a risk factor for hepatic decompensation (Mauss et al 2004). Furthermore, didanosine use has been significantly associated with worsening of liver fibrosis (OR 3.34; 95\% CI 1.39-7.96; $\mathrm{p}=0.007$ ) in the RIBAVIC study population, prompting the authors to suggest that anti-HCV therapy should precede the administration of HAART (Bani-Sadr et al 2008b).

Earlier recognition of these drug interactions provided benefit in subsequent studies. In particular, in the PRESCO trial, didanosine use was excluded, and only 2 patients stopped anti-HCV therapy due to symptomatic mitochondrial toxicity, while there were no cases of hepatic decompensation. The authors conclude, "Avoidance of didanosine, limited use of zidovudine and therapy restricted to patients with
CD4+ T-cell counts $>300$ cells/mL most probably explains the lower and different spectrum of serious adverse events in PRESCO compared with prior trials conducted in coinfected patients." (Soriano et al 2007a).

On the basis of these known toxicities, a few recommendations can be made for coinfected patients in whom anti-HCV therapy is to be initiated. If other antiretroviral regimens are available, zidovudine should be discontinued. If zidovudine must be continued, it is recommended to monitor hemoglobin levels closely for significant anemia (Sulkowski 2008). In the case of didanosine, concomitant treatment with ribavirin is contraindicated (Soriano et al 2007b).

\section{Enhancing antiviral responses}

Studies and experience with HCV mono-infected patients suggest a number of details that can enhance response to antiviral therapy. Although it is clear that genotype 2 and 3 infected patients have higher rates of SVR, it has recently been noted that some patients with these "favorable" genotypes may require more extensive treatment than the currently recommended 24 weeks (Berg et al 2006). Longer therapy has been suggested in those patients failing to reach the endpoint of early or rapid virologic response, while shorted duration has been suggested for genotype 2 and 3 patients with prompt eradication of circulating viremia (Dalgard and Mangia 2006). The use of weight-based ribavirin dosing, especially in heavier patients, may enhance response compared with flat ribavirin dosing. The important contribution of ribavirin in providing virologic response necessitates extreme caution with, if not complete avoidance of, zidovudine and abacavir.

The use of growth factors, especially erythropoietin, can maintain hematocrit during therapy, but has yet to be definitively shown to enhance SVR rates. In the HIV - HCV coinfected patients, tailored duration of therapy and weightbased ribavirin dosing have shown promise, but will require more rigorous scrutiny in the coming years. Erythropoietin has been shown to allow higher ribavirin rates and improved quality of life scores in coinfected patients on antiviral therapy and was well tolerated. Similar to the situation with monoinfected patients, erythropoietin has not been shown to effect SVR (Afdhal et al 2004; Sulkowski et al 2005).

\section{Future therapeutic options}

As the life cycle of $\mathrm{HCV}$ is better understood, the following model has been promulgated: HCV binding to a cell surface receptor, internalization into the host cell, cytoplasmic release and uncoating of the viral RNA genome, internal ribosome entry site-mediated translation and polyprotein processing by 
cellular and viral proteases, RNA replication, packaging and assembly, and virion maturation and release from the host cell (Moradpour and Blum 2004). A number of nonstructural proteins have been identified and characterized, providing potential strategies for therapeutic intervention. For example, the NS3 serine protease (Lamarre et al 2003) and the NS5B RNA dependent RNA polymerase (Lesburg et al 1999) have emerged as potential targets for antiviral therapies. Drug development has been hampered by the difficulty of the HCV protease binding site, viral mutation and the development of toxicity in animal trials. To date several drugs are emerging from phase II clinical trials into larger studies. It is becoming apparent that combination therapy with a number of antiviral drugs and perhaps immunomodulatory agents will be required to supplant IFN as the therapy of choice. The use of these newer agents in coinfected patients has not yet been reported.

\section{Conclusions}

The existing literature definitively demonstrates that optimal treatment of $\mathrm{HCV}$ in $\mathrm{HIV}-\mathrm{HCV}$ coinfected patients requires the combination of pegylated IFN with ribavirin. Furthermore, the overall response rates are lower than in patients with $\mathrm{HCV}$ alone, particularly for patients with HCV genotype 1 or high pretreatment viral load. Predictors of response include genotype, baseline HCV RNA level, and undetectable HCV RNA at week 4. The newer PRESCO data indicate that weight-based ribavirin dosing results in higher SVR rates, though still less than those for HCV-monoinfected patients, and does not cause higher toxicity. Pegylated IFN combined with weight-based ribavirin is appropriate and safe for treatment of HCV in HIV$\mathrm{HCV}$ coinfected patients. Nucleoside reverse transcriptase inhibitors, including abacavir, zidovudine, and especially didanosine, should be discontinued before initiation of ribavirin therapy. Patients infected with HCV genotypes 2 and 3 and RVR could benefit from shorter ( 24 weeks) courses of therapy, based on PRESCO data, but current consensus guidelines still mandate 48 weeks for all patients, regardless of genotype. Similarly, patients with HCV genotypes 1 and 4 and early or slow virologic response, but not RVR, may benefit from extended (60-72 weeks) courses of therapy. Patients without early virologic response at 12 weeks should be advised of the extremely low likelihood of SVR, and discontinuation of therapy should be considered, until results of ongoing maintenance trials are available. The demonstration of histologic response even in the absence of SVR does provide a rationale for maintenance therapy currently being evaluated.

Finally, newer agents that have specific activity against the HCV virion are currently in phase 1 and 2 trials. Targets such as the serine protease and the RNA-dependent RNA polymerase proteins are similar to those of HAART therapy in the HIV virion, suggesting possible overlap in coinfected patients. Further studies will certainly be needed to elucidate the nature of such an interaction.

\section{Disclosures}

Ravinder Dhillon has nothing to disclose.

Simona Rossi has received research support from BristolMyers, Human Genome Sciences, McNeil, Roche Laboratories, Sanofi-Aventis, and Schering-Plough.

Steven K Herrine has received research support from Bristol-Myers, Human Genome Sciences, McNeil, Roche Laboratories, Sanofi-Aventis, and Schering-Plough, and speaking honoraria from Roche Laboratories and Schering-Plough.

\section{References}

Afdhal NH, Dieterich DT, Pockros PJ, et al. 2004. Epoetin alfa maintains ribavirin dose in HCV-infected patients: a prospective, double-blind, randomized controlled study. Gastroenterology, 126:1302-11.

Alter MJ. 2006. Epidemiology of viral hepatitis and HIV co-infection. J Hepatol, 44(Suppl):S6-S9.

Alvarez D, Dieterich DT, Brau N, et al. 2006. Zidovudine use but not weight-based ribavirin dosing impacts anaemia during $\mathrm{HCV}$ treatment in HIV-infected persons. $J$ Viral Hepat, 13:683-9.

Bani-Sadr F, Carrat F, Pol S, et al. 2005a. Risk factors for symptomatic mitochondrial toxicity in $\mathrm{HIV} /$ hepatitis $\mathrm{C}$ virus-coinfected patients during interferon plus ribavirin-based therapy. J Acquir Immune Defic Syndr, 40:47-52.

Bani-Sadr F, Carrat F, Rosenthal E, et al. 2005b. Spontaneous hepatic decompensation in patients coinfected with HIV and hepatitis C during interferon-ribavirin combination treatment. Clin Infect Dis, 41:1806-9.

Bani-Sadr F, Denoeud L, Morand P, et al. 2007a. Early virologic failure in HIV-coinfected hepatitis $\mathrm{C}$ patients treated with the peginterferonribavirin combination: does abacavir play a role? J Acquir Immune Defic Syndr, 45:123-5.

Bani-Sadr F, Goderel I, Penalba C, et al. 2007b. Risk factors for anaemia in human immunodeficiency virus/hepatitis $\mathrm{C}$ virus-coinfected patients treated with interferon plus ribavirin. J Viral Hepat, 14:639-44.

Bani-Sadr F, Lapidus N, Bedossa P, et al. 2008a. Progression of fibrosis in HIV and hepatitis $C$ virus-coinfected patients treated with interferon plus ribavirin-based therapy: analysis of risk factors. Clin Infect Dis, 46:768-74.

Bani-Sadr F, Lapidus N, Melchior JC, et al. 2008b. Severe weight loss in $\mathrm{HIV} / \mathrm{HCV}$-coinfected patients treated with interferon plus ribavirin: incidence and risk factors. J Viral Hepat, 15:255-60.

Barreiro P, Simarro N, Nuñez M, et al. 2006. Sustained virological response following HCV therapy is associated with regression of liver fibrosis in $\mathrm{HCV} / \mathrm{HIV}$-co-infected patients [abstract 859]. Presented at 13th Conference on Retroviruses and Opportunistic Infections; Denver, Colorado.

Barth H, Liang TJ, Baumert TF. 2004. Hepatitis C virus entry: molecular biology and clinical implications. Hepatology, 44:527-35.

Bekisz J, Schmeisser H, Hernandez J, et al. 2004. Human interferons alpha, beta and omega. Growth Factors, 22:243-51.

Benhamou Y, Bochet M, Di Martino V, et al. 1999. Liver fibrosis progression in human immunodeficiency virus and hepatitis $\mathrm{C}$ virus coinfected patients. Hepatology, 30:1054-8.

Berg T, von Wagner M, Nasser S, et al. 2006. Extended treatment duration for hepatitis $C$ virus type 1: comparing 48 versus 72 weeks of peginterferon-alfa-2a plus ribavirin. Gastroenterology, 130:1086-97.

Bica I, McGovern B, Dhar R, et al. 2001. Increasing mortality due to endstage liver disease in patients with human immunodeficiency virus infection. Clin Infect Dis, 32:492-7. 
Carrat F, Bani-Sadr F, Pol S, et al. 2004. Pegylated interferon alfa-2b vs standard interferon alfa- $2 b$, plus ribavirin, for chronic hepatitis $\mathrm{C}$ in HIVinfected patients: a randomized controlled trial. JAMA, 292:2839-48.

Chung RT, Andersen J, Volberding P, et al. 2004. Peginterferon alfa-2a plus ribavirin versus interferon alfa-2a plus ribavirin for chronic hepatitis $\mathrm{C}$ in HIV-confected persons. $N$ Engl J Med, 351:451-9.

Daar ES, Lynn H, Donfield S, et al. 2001. Relation between HIV-1 and hepatitis $\mathrm{C}$ viral load in patients with hemophilia. $J$ Acquir Immune Defic Syndr, 26:466-72.

Dalgard O, Mangia A. 2006. Short-term therapy for patients with hepatitis C virus genotype 2 or 3 infection. Drugs, 66:1807-15.

de Veer MJ, Holko M, Frevel M, et al. 2001. Functional classification of interferon-stimulated genes identified using microarrays. J Leukocyte Biol, 69:912-20.

Feld JJ, Hoofnagle JH. 2005. Mechanism of action of interferon and ribavirin in treatment of hepatitis C. Nature, 436:967-72.

Fried MW, Shiffman ML, Reddy R, et al. 2002. Peginterferon alfa-2a plus ribavirin for chronic hepatitis C virus infection. N Engl J Med, 347:975-82.

Gale M Jr. 2003. Effector genes of interferon action against hepatitis C virus. Hepatology, 37:975-8.

Graham CS, Baden LR, Yu E, et al. 2001. Influence of human immunodeficiency virus infection on the course of hepatitis $\mathrm{C}$ virus infection: a meta-analysis. Clin Infect Dis, 33:562-9.

Greub G, Ledergerber B, Battegay M, et al. 2000. Clinical progression, survival, and immune recovery during antiretroviral therapy in patients with HIV-1 and hepatitis C virus coinfection: the Swiss HIV Cohort Study. Lancet, 356:1800-5.

Jacobson IM, Brown RS Jr, McCone J, et al. 2007. Impact of weight-based ribavirin with peginterferon alfa- $2 \mathrm{~b}$ in African Americans with hepatitis C virus genotype 1. Hepatology, 46:982-90.

Janssen HL, Brouwer JT, van der Mast RC, et al. 1994. Suicide associated with alfa-interferon therapy for chronic viral hepatitis. $J$ Hepatol, 21:241-3.

Labarga 2007.

Lafeuillade A, Hittinger G, Chadapaud S. 2001. Increased mitochondrial toxicity with ribavirin in HIV/HCV coinfection. Lancet, 357:280-1.

Laguno M, Murillas J, Blanco JL, et al. 2004. Peginterferon alfa-2b plus ribavirin compared with interferon alfa- $2 \mathrm{~b}$ plus ribavirin for treatment of HIV/HCV co-infected patients. AIDS, 18:F27-F36.

Lamarre D, Anderson PC, Bailey M, et al. 2003. An NS3 protease inhibitor with antiviral effects in humans infected with hepatitis $\mathrm{C}$ virus. Nature, 426:186-9.

Lau DT, Kleiner DE, Ghany MG, et al. 1998. 10-Year follow-up after interferon-alpha therapy for chronic hepatitis C. Hepatology, 28:1121-27.

Lesburg CA, Cable MB, Ferrari E, et al. 1999. Crystal structure of the RNA-dependent RNA polymerase from hepatitis $C$ virus reveals a fully encircled active site. Nat Struct Biol, 6:937-43.

McGovern B, Bica I. 2002. Risk of HAART therapy in hepatitis C. Hepatology, 35:730.

McGovern B. 2004. HAART and hepatic safety. J Int Assoc Physicians AIDS Care, 3(Suppl):S23-S42.

McGovern BH. 2007. Hepatitis C in the HIV-infected patient. J Acquir Immune Defic Syndr, 45 (Suppl 2):S47-56.

McHutchison JG, Gordon SC, Schiff ER, et al. 1998. Interferon alfa-2b alone or in combination with ribavirin as initial treatment for chronic hepatitis C. N Engl J Med, 339:1485-92.

Manns MP, McHutchison JG, Gordon SC, et al. 2001. Peginterferon alfa-2b plus ribavirin compared with interferon alfa- $2 \mathrm{~b}$ plus ribavirin for initial treatment of chronic hepatitis C: a randomised trial. Lancet, 358:958-65.

Mauss S, Valenti W, DePamphilis J, et al. 2004. Risk factors for hepatic decompensation in patients with HIV/HCV coinfection and liver cirrhosis during interferon-based therapy. AIDS, 18:F21-25.

Moradpour D, Blum HE. 2004. A primer on the molecular virology of hepatitis C. Liver Int, 24:519-25.

Nunez M, Marino A, Miralles C, et al. 2007b. Baseline hepatitis C virus RNA and response at week 4 are the best predictors of relapse after treatment with pegylated interferon plus ribavirin in HIV/hepatitis $\mathrm{C}$ virus-coinfected patients. J Acquir Immune Defic Syndr, 45:439-44.
Nunez M, Miralles C, Berdun MA, et al. 2007a. Role of weight-based ribavirin dosing and extended duration of therapy in chronic hepatitis C in HIV-infected patients: the PRESCO trial. AIDS Res Hum Retroviruses, 23:972-82.

Payan C, Pivert A, Morand P, et al. 2007. Rapid and early virological response to chronic hepatitis $C$ treatment with IFN alpha-2b or PEG-IFN alpha- $2 b$ plus ribavirin in HIV/HCV co-infected patients. Gut, 56:1111-6.

Pol S, Nalpas B, Bourliere M, et al. 2000. Combination of ribavirin and interferon-alfa surpasses high doses of interferon-alfa alone in patients with genotype-1b-related chronic hepatitis C. Hepatology, 31:1338-44.

Poynard T, Leroy V, Cohard M, et al. 1996. Meta-analysis of interferon randomized trials in the treatment of viral hepatitis $\mathrm{C}$ : effects of dose and duration. Hepatology, 24:778-89.

Poynard T, McHutchison J, Manns M, et al. 2002. Impact of pegylated interferon-alfa- $2 \mathrm{~b}$ and ribavirin on liver fibrosis in patients with chronic hepatitis C. Gastroenterology, 122:1303-13.

Puoti C, Magrini A, Stati T, et al. 1997. Clinical, histological, and virological features of hepatitis $\mathrm{C}$ virus carriers with persistently normal or abnormal alanine transaminase levels. Hepatology, 26:1393-8.

Rauch A, Rickenbach M, Weber R, et al. 2005. Unsafe sex and increased incidence of hepatitis $\mathrm{C}$ virus infection among HIV-infected men who have sex with men: the Swiss HIV Cohort Study. Clin Infect Dis, 41:395-402.

Re VL 3rd, Kostman JR, Gross R, et al. 2007. Incidence and risk factors for weight loss during dual HIV/hepatitis $\mathrm{C}$ virus therapy. J Acquir Immune Defic Syndr, 44:344-50.

Schaefer M, Schwaiger M, Garkisch AS, et al. 2005. Prevention of interferon-alpha associated depression in psychiatric risk patients with chronic hepatitis C. J Hepatol, 42:793-8.

Sen GC. 2001. Viruses and interferons. Annu Rev Microbiol, 55:255-81.

Sherman KE, Rouster SD, Chung RT, et al. 2002. Hepatitis C virus prevalence among patients infected with human immunodeficiency virus: a cross-sectional analysis of the US Adult AIDS Clinical Trials Group. Clin Infect Dis, 34:831-7.

Shuhart MC. 2007. Hepatitis C and HIV coinfection. Curr Hepatitis Rep, 6:46-53

Soriano V, Miralles C, Berdun MA, et al. 2007a. Premature treatment discontinuation in $\mathrm{HIV} / \mathrm{HCV}$-coinfected patients receiving pegylated interferon plus weight-based ribavirin. Antivir Ther, 12:469-76.

Soriano V, Puoti M, Sulkowski M, et al. 2007b. Care of patients coinfected with HIV and hepatitis C virus: 2007 updated recommendations from the HCV-HIV international panel. AIDS, 21:1073-89.

Sulkowski MS. 2008. Viral hepatitis and HIV coinfection. J Hepatol, 48:353-67.

Sulkowski MS, Dieterich DT, Bini EJ, et al. 2005. Epoetin alfa once weekly improves anemia in HIV/hepatitis $\mathrm{C}$ virus-coinfected patients treated with interferon/ribavirin: a randomized controlled trial. $J$ Acquir Immune Defic Syndr, 39:504-6.

Taylor L, Schwartzapfel B, Allen S, et al. 2003. Extending treatment for $\mathrm{HCV}$ infection to HIV-HCV coinfected individuals with psychiatric illness and drug dependence. Clin Infect Dis, 36:1501-2.

Thomas DL. 2002. Hepatitis C and human immunodeficiency virus infection. Hepatology, 36(Suppl 1):S201-S9.

Tilg H. 1997. New insights into the mechanisms of interferon: an immunoregulatory and anti-inflammatory cytokine. Gastroenterology, 112:1017-21.

Torriani FJ, Rodriguez-Torres M, Rockstroh JK, et al. 2004. Peginterferon alfa-2a plus ribavirin for chronic hepatitis $\mathrm{C}$ virus infection in HIVinfected patients. $N$ Engl J Med, 351:438-50.

Vispo E BP, Maida I, Pineda J, et al. 2007. Abacavir-containing HAART reduces the chances for sustained virologic response to pegylatedinterferon plus ribavirin in HIV-infected patients with chronic hepatitis C [abstract]. Third International Workshop on HIV and Hepatitis Coinfection, Abstract 46.

Wills RJ. 1990. Clinical Pharmacology of interferons. Clin Pharmacokin, 19:390-9. 